\title{
Amblyopia in 4-year-old children treated with grating stimulation and full-time occlusion; a comparative study
}

\author{
GUNNAR LENNERSTRAND ${ }^{1}$ AND BERIT SAMUELSSON ${ }^{2}$ \\ From the Departments of Ophthalmology, 'Linköping University Hospital, ${ }^{2}$ Malmö General Hospital, and \\ 'Umeå University Hospital
}

SUMMARY We have compared the effects on visual acuity and binocular functions of grating stimulation (CAM therapy) and full-time occlusion in 38 4-year-old, previously untreated amblyopic children. The patients were divided into subgroups with regard to amblyopia type and fixation pattern. We found that grating stimulation was slightly better than occlusion in improving visual acuity of anisometropic amblyopes with central fixation, but that both types of therapy were equally effective in strabismic amblyopia with central fixation and in amblyopia with eccentric fixation. However, maximal treatment effects were not reached with grating stimulation alone, as shown at follow-up after continued conventional therapy. Grating stimulation may be regarded as a valuable method at the initiation of treatment, particularly in anisometropic amblyopia, but it has to be supplemented with occlusion, which still must be regarded as the prime form of amblyopia therapy.

The treatment of amblyopia with grating stimulation (the CAM stimulation, introduced by Campbell $e t$ al.') has been evaluated in several studies, but the effectiveness of the treatment is still under debate. The treatment implies short, repeated stimulations of the amblyopic eye with rotating grating patterns. During these treatment periods the best eye is occluded and the child preoccupied with drawing or other near distance activities. No occlusion is exercised between treatment sessions. The results of CAM treatment reported by different groups have been reviewed recently. ${ }^{2}$ From controlled studies it seems doubtful whether the grating pattern contributed to the visual improvement. It appeared more likely that it was the partial occlusion and the concentrated preoccupation with close work and visually demanding tasks that produced the increase in visual acuity that has been reported. We started the present study before these findings had been published, and have therefore used the original CAM stimulation procedures.

The purpose of this study was to compare the effects of CAM and full-time occlusion in 4-year-old children

Correspondence to Dr Gunnar Lennerstrand, Department of Ophthalmology, University Hospital, S-90185 Umeå, Sweden. with newly discovered and previously untreated amblyopia. The children were grouped with respect to aetiology of their amblyopia, whether strabismic or anisometropic, and with respect to fixation pattern, since these factors may influence the prognosis for visual improvement. The children were followed up for at least 6 months. The materials of most previous studies have been rather heterogeneous with regard to the patients' age, amblyopia type, and extent of amblyopia therapy before CAM. Nyman et al. ${ }^{3}$ have also studied 4-year-old amblyopes but did not subdivide the patients into different amblyopia categories and had a shorter follow-up.

Time factors are of great concern in amblyopia treatment. The first period is the hardest for the child to endure. The study by Nyman et al. ${ }^{3}$ indicated that CAM can improve visual acuity at the same rate as full-time occlusion. We wanted to see if this effect was the same in the different types of amblyopia. We also wanted to study long-term effects of amblyopia therapy in the different subgroups.

\section{Material and methods}

Thirty-eight 4-year-old children with amblyopia, but otherwise healthy, participated in the study, 14 girls 
Table 1A Anisometropia with central fixation; CAM treatment

\begin{tabular}{|c|c|c|c|c|c|c|c|c|c|}
\hline \multirow[t]{2}{*}{ Pat. } & \multirow[t]{2}{*}{ Sex } & \multicolumn{2}{|c|}{$\begin{array}{l}\text { Distance } V A \text { before } \\
\text { treatm. }\end{array}$} & \multicolumn{3}{|c|}{$\begin{array}{l}\text { Distance VA (change in \%) } \\
\text { End of CAM }\end{array}$} & \multicolumn{3}{|c|}{ Follow-up 3 months } \\
\hline & & Amblyopic & Best & Amblyopic & Best & Effect $(\%)$ & Amblyopic & Best & Effect $(\%)$ \\
\hline 1 & $\mathbf{M}$ & 0.7 & 1.0 & $1 \cdot 0(40)$ & $1 \cdot 0(0)$ & 40 & $*$ & $*$ & $*$ \\
\hline 2 & $\mathbf{M}$ & 0.5 & $1 \cdot 0$ & $1 \cdot 0(100)$ & $1 \cdot 0(0)$ & 100 & $0 \cdot 7(40)$ & $1 \cdot 0(0)$ & 40 \\
\hline 3 & $\mathbf{M}$ & 0.5 & $0 \cdot 8$ & $1 \cdot 0(100)$ & $0 \cdot 8(0)$ & 100 & $1 \cdot 0(100)$ & $1 \cdot 0(25)$ & 75 \\
\hline 4 & $\mathbf{M}$ & $0 \cdot 4$ & $0 \cdot 8$ & $0.6(50)$ & $0 \cdot 8(0)$ & 50 & $0.7(75)$ & $0.8(0)$ & 75 \\
\hline 5 & $\mathbf{M}$ & $0 \cdot 4$ & $0 \cdot 9$ & $0 \cdot 7(75)$ & $0.9(0)$ & 75 & $0 \cdot 8(100)$ & $0 \cdot 9(0)$ & 100 \\
\hline 6 & $\mathbf{F}$ & $0 \cdot 3$ & $0 \cdot 7$ & $0 \cdot 3(0)$ & $0 \cdot 7(0)$ & 0 & $0 \cdot 6(100)$ & $0 \cdot 6(-14)$ & 100 \\
\hline 7 & $\mathbf{M}$ & 0.5 & $0 \cdot 8$ & $0 \cdot 8(60)$ & $0 \cdot 9(12)$ & 48 & $0 \cdot 9(80)$ & $0 \cdot 9(12)$ & 68 \\
\hline 8 & $\mathbf{F}$ & $0 \cdot 5$ & $0 \cdot 8$ & $0 \cdot 8(60)$ & $0 \cdot 8(0)$ & 60 & $0 \cdot 8(60)$ & $0 \cdot 8(0)$ & 60 \\
\hline \multirow[t]{2}{*}{9} & $\mathbf{F}$ & $0 \cdot 3$ & 0.9 & $0 \cdot 8(167)$ & $1 \cdot 0(11)$ & 156 & $0 \cdot 5(67)$ & $0 \cdot 8(-11)$ & 67 \\
\hline & & $0 \cdot 46 \pm 0 \cdot 12$ & $0 \cdot 86 \pm 0 \cdot 10$ & $0 \cdot 78 \pm 0 \cdot 23$ & $0 \cdot 89 \pm 0 \cdot 11$ & $69 \cdot 9 \pm 44 \cdot 7$ & $0 \cdot 76 \pm 0 \cdot 16$ & $0 \cdot 85 \pm 0 \cdot 13$ & $73 \cdot 1 \pm 20 \cdot 0$ \\
\hline
\end{tabular}

Distance VA given in both absolute values and in change in percent of initial VA value. Near VA given as Jaeger equivalent. Binocular function: represented a stereoscopic threshold in sec arc, or as fusion (+) or exclusion (-) with Bagolini glasses. Asterisk $\left(^{*}\right)$ indicates test not done. Belon each column mean \pm SD presented. Abbreviation: ET esotropia; XT. exotropia. Occlusion implies full-time facial occlusion; 'Einschleich' the use of dimming filter in front of best eye; 'Atropine' daily instillation into the best eye.

and 24 boys. Visual screening is performed on all 4-year-old children in Sweden at the child health care centres. Children with subnormal vision in the Linköping and Malmö regions were referred to the departments of ophthalmology for further evaluation. The Linköping and Malmö patients consisted of 19 children each. All 4-year-old children that fulfilled the amblyopia criteria described below, and accepted treatment for 6 months, entered the study, which was conducted between November 1980 and March 1982.

Ophthalmological testing and amblyopia grouping. A general ophthalmological examination and cycloplegic retinoscopy was performed and glasses were prescribed when needed. Vision was retested when the child had been wearing the glasses for at least 5 weeks. On this occasion an orthoptic evaluation was also performed. Visual acuity at distance was tested with a Snellen E chart or a letter matching chart described by Hedin et al. ${ }^{4}$ Near visual acuity was tested with an $E$ chart for near vision graded according to the Jaeger (J) scale, J1 representing the smallest and J13 the largest print. Binocular functions were assessed with the Bagolini striated glasses and with the Titmus and TNO stereo tests. The same stereo test was used in all examinations of an individual child.

Amblyopia was diagnosed if a difference in visual acuity of at least 2 lines existed between eyes and no organic cause for the visual loss could be discovered. Amblyopia was subdivided into different types with regard to occurrence of anisometropia and strabismus, and depending on the fixation pattern. The subgroups represented in our material are shown in Tables 1-3. Most children had anisometropic or strabismic amblyopia with central fixation. Anisometropia implied a difference in refraction between eyes of 2 dioptres or more in spherical power and one dioptre or more of cylinder. Microstrabismus

Table 1B Anisometropia with central fuxation; occlusion treatment (for explanation see Table 1A)

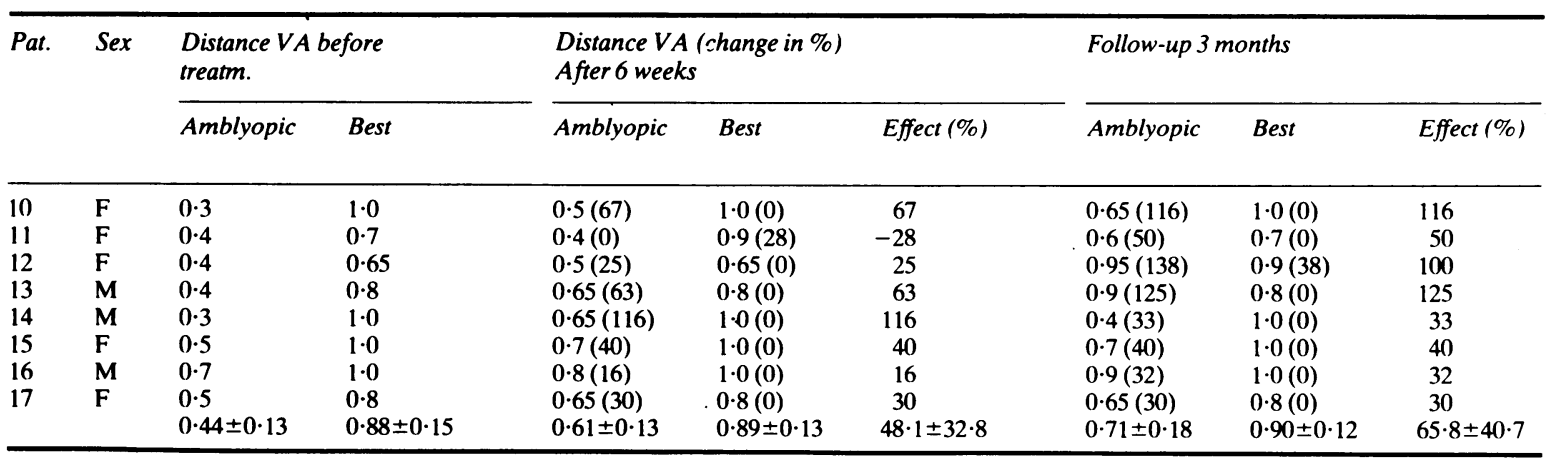




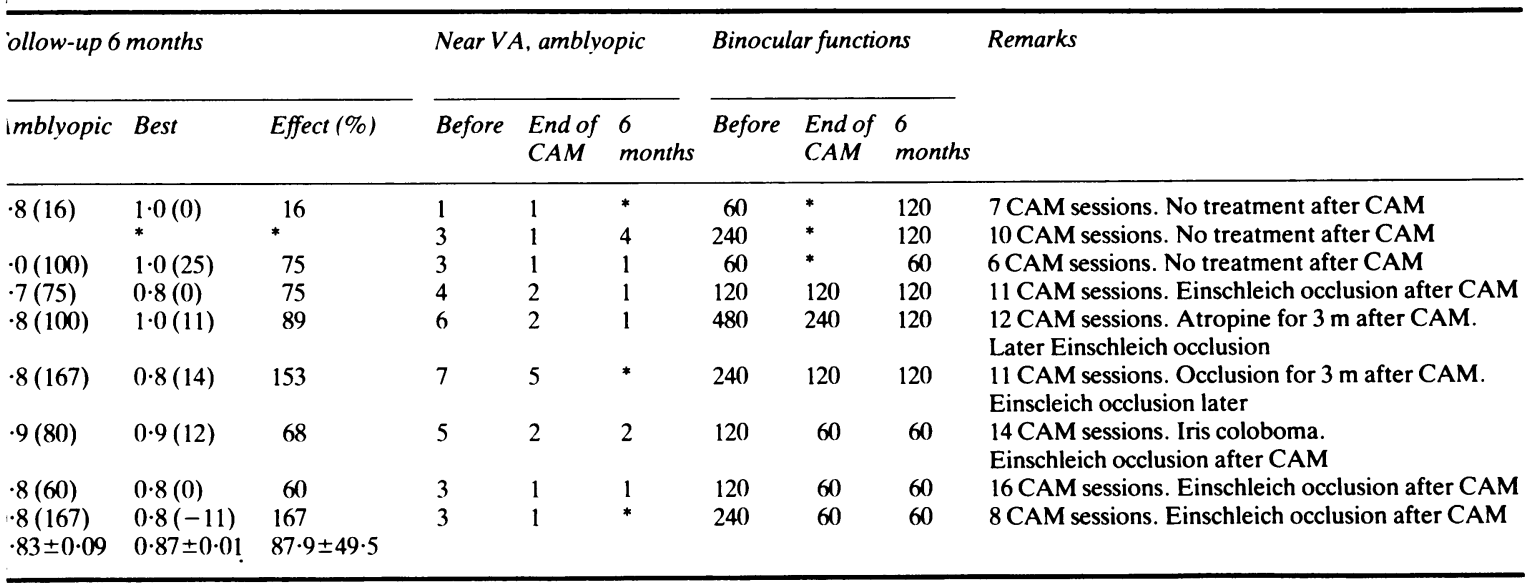

was referred to the strabismic group. The fixation pattern was established with the aid of the visuoscope. In each subgroup the children were randomly started with CAM treatment or full-time occlusion, although geographical factors (residence far from the hospital) made it impossible to choose CAM in some cases.

The procedures of this study were approved by the ethical committees of the hospitals.

Treatment and follow-up. In the CAM group grating stimulation with the CAM apparatus was performed once or twice a week. The procedures of treatment followed largely the recommendations of Watson et $a l^{5}$ and have been described by Lennerstrand et al. ${ }^{6}$ The number of treatment sessions was between 6 and 16, depending on the effect on visual acuity. The number of treatments for individual children are listed in the Tables. The CAM treatment lasted between 4 and 8 weeks. If acuity did not change for 3 consecutive sessions, CAM treatment was terminated. Visual acuity was tested after each session. At the end of the CAM treatment period another orthoptic evaluation was performed. Most children were then started on conventional amblyopia therapy, as seen in the Tables, since it is our experience from a previous study that visual acuity will usually deteriorate without further treatment. ${ }^{6}$

In the control group amblyopia treatment consisted of full-time facial occlusion or occlusion with dimming (Einschleich) filters. Einschleich occlusion was introduced when amblyopia was fairly light and facial occlusion was badly accepted by the child. The children treated with occlusion therapy were examined 6 weeks after the start of treatment.

Follow-up examinations were done at regular intervals. The results at 3 and 6 months from the start of treatment are shown in the Tables. A few children failed to appear at these occasions.

\section{Results}

VISUAL ACUITY OF THE BEST EYE

Visual acuity in children will improve with age and increasing maturity as well as with practice. Measured over all groups of 4-year-old children a slight increase

\begin{tabular}{|c|c|c|c|c|c|c|c|c|c|}
\hline \multicolumn{3}{|c|}{ Follow-up 6 months } & \multicolumn{3}{|c|}{ Near $V A$, amblyopic } & \multicolumn{3}{|c|}{ Binocular functions } & \multirow[t]{2}{*}{ Remarks } \\
\hline Amblyopic & Best & Effect $(\%)$ & Before & $\begin{array}{l}\text { After } \\
6 \text { weeks }\end{array}$ & $\begin{array}{l}6 \\
\text { months }\end{array}$ & Before & $\begin{array}{l}\text { After } \\
6 \text { weeks }\end{array}$ & $\begin{array}{l}6 \\
\text { months }\end{array}$ & \\
\hline$) \cdot 65(116)$ & $1 \cdot 0(0)$ & 116 & * & 3 & 1 & 240 & 120 & 60 & Occlusion \\
\hline$) \cdot 6(50)$ & $0.9(28)$ & 22 & 3 & $*$ & 2 & 120 & 120 & 120 & Occlusion, only partly successful \\
\hline$\cdot 0(167)$ & $1 \cdot 0(54)$ & 113 & * & 3 & 1 & 120 & 120 & 60 & Occlusion \\
\hline$) .9(125)$ & $0 \cdot 9(12)$ & 113 & 2 & $*$ & 2 & 60 & 120 & 60 & Occlusion \\
\hline$\cdot 0(233)$ & $1 \cdot 0(0)$ & 233 & 6 & 3 & 1 & 120 & 60 & 60 & Occlusion, but refused 6 weeks -3 months \\
\hline$) .9(80)$ & $1 \cdot 0(0)$ & 80 & 5 & $*$ & 1 & 60 & 60 & 60 & Occlusion, but refused 6 weeks -3 months \\
\hline$) \cdot 9(32)$ & $1 \cdot 0(0)$ & 32 & * & 3 & 1 & 60 & 60 & 60 & Einschleich occlusion \\
\hline$) \cdot 65(30)$ & $0 \cdot 8(0)$ & 30 & $*$ & $*$ & $*$ & 480 & 120 & 120 & Occlusion \\
\hline$) \cdot 83 \pm 0 \cdot 16$ & $0.95 \pm 0.08$ & $92 \cdot 4 \pm 69 \cdot 5$ & & & & & & & \\
\hline
\end{tabular}


Table 2A Strabismus with central fuxation; CAM treatment (for explanation see Table 1A)

\begin{tabular}{|c|c|c|c|c|c|c|c|c|c|}
\hline \multirow[t]{2}{*}{ Pat. } & \multirow[t]{2}{*}{ Sex } & \multicolumn{2}{|c|}{$\begin{array}{l}\text { Distance VA before } \\
\text { treatm. }\end{array}$} & \multicolumn{3}{|c|}{$\begin{array}{l}\text { Distance VA (change in \%) } \\
\text { End of } C A M\end{array}$} & \multicolumn{3}{|c|}{ Follow-up 3 months } \\
\hline & & Amblyopic & Best & Amblyopic & Best & Effect $(\%)$ & Amblyopic & Best & Effect $(\%)$ \\
\hline 18 & $\mathbf{M}$ & 0.5 & $0 \cdot 8$ & $1 \cdot 0(100)$ & $0 \cdot 9(12)$ & 88 & $0 \cdot 9(80)$ & $1 \cdot 0(25)$ & 55 \\
\hline 20 & $\mathbf{M}$ & 0.4 & $0 \cdot 8$ & $0.65(63)$ & $0 \cdot 8(0)$ & 63 & $0.5(25)$ & $0 \cdot 8(0)$ & 25 \\
\hline 21 & $\mathbf{F}$ & $0 \cdot 1$ & 0.8 & $0 \cdot 2(100)$ & $0 \cdot 7(-12)$ & 100 & $0 \cdot 4(300)$ & $0 \cdot 7(-12)$ & 300 \\
\hline 22 & $\mathbf{M}$ & $0 \cdot 2$ & 0.5 & $0.3(50)$ & $0.5(0)$ & 50 & $0.4(100)$ & $0 \cdot 5(0)$ & 100 \\
\hline 23 & $\mathrm{~F}$ & $0 \cdot 3$ & $0 \cdot 8$ & $0.5(67)$ & $0.8(0)$ & 67 & $0 \cdot 6(100)$ & $0.8(0)$ & 100 \\
\hline \multirow[t]{2}{*}{24} & $\mathbf{M}$ & $0 \cdot 1$ & $1 \cdot 0$ & $0 \cdot 2(100)$ & $1 \cdot 0(0)$ & 100 & $0.4(300)$ & $1 \cdot 0(0)$ & 300 \\
\hline & & $0 \cdot 29 \pm 0 \cdot 16$ & $0 \cdot 76 \pm 0 \cdot 16$ & $0.48 \pm 0.29$ & $0 \cdot 76 \pm 0 \cdot 17$ & $70 \cdot 4 \pm 27 \cdot 7$ & $0 \cdot 56 \pm 0 \cdot 19$ & $0 \cdot 77 \pm 0 \cdot 18$ & $135 \cdot 3 \pm 115$ \\
\hline
\end{tabular}

of visual acuity in the nonamblyopic eye was observed. The acuity rose from $0 \cdot 77 \pm 0 \cdot 15$ at the initial testing to $0 \cdot 84 \pm 0 \cdot 14$ at the 6 -month follow-up, but the difference was not statistically significant. The results in the different subgroups are shown in the Tables. For unknown reasons the acuities were generally higher in anisometropic (Table 1) than in strabismic patients (Table 2), but the relative increase in acuity with time was the same.

In the assessment of treatment effects in the amblyopic eye the visual acuity results have been corrected for time-dependent changes in acuity of the best eye. We have not been able to determine to what extent amblyopia treatment might retard visual development of the best eye, but could study only the overall effect of treatment, age, and practice. For this reason increases in acuity of the best eye, measured as a percentage of the initial values for this eye, have been subtracted from the changes in percentage obtained for the amblyopic eye.

DISTANCE VISUAL ACUITY IN THE AMBLYOPIC EYE The initial values of visual acuity within each diagnostic group were the same for children treated with CAM and occlusion as seen in Fig. 1 and the Tables and verified by Student's $t$ test. Visual acuity of the amblyopic eye was generally higher for anisometropic than for strabismic amblyopia with central fixation $(p<0.05)$. It was much lower in children with eccentric fixation (Table 3 ).

During the first period of treatment visual acuity increased above the initial value with both CAM and occlusion (Fig. 1). This effect was statistically significant $(p<0 \cdot 01)$. As seen in Table 2 the effects of treatment were equal for both CAM and occlusion in children with strabismus and central fixation. However, a difference between treatment types was observed for children with anisometropia and central fixation (Table 1). They seemed to improve somewhat more with CAM than with occlusion $(p=0 \cdot 05)$. Measured over all groups the effects of treatment were the same for occlusion as for CAM. After the first treatment period occlusion was instituted in most children treated with CAM. In one child with strabismus and in 2 out of 3 children with anisometropia, in whom all treatment after CAM was abandoned, visual acuity remained stationary during follow-up (Tables 1 and 2). In one child with anisometropia and no further treatment after CAM vision dropped slightly (Table 1). Occlusion was maintained in all children started with this type of therapy.

Table 2B Strabismus with central fuxation; occlusion treatment (for explanation see Table 1A)

\begin{tabular}{|c|c|c|c|c|c|c|c|c|c|}
\hline \multirow[t]{2}{*}{ Pat. } & \multirow[t]{2}{*}{ Sex } & \multicolumn{2}{|c|}{$\begin{array}{l}\text { Distance } V A \text { before } \\
\text { treatm. }\end{array}$} & \multicolumn{3}{|c|}{$\begin{array}{l}\text { Distance VA (change in \%) } \\
\text { After } 6 \text { weeks }\end{array}$} & \multicolumn{3}{|c|}{ Follow-up 3 months } \\
\hline & & Amblyopic & Best & Amblyopic & Best & Effect $(\%)$ & Amblyopic & Best & Effect $(\%)$ \\
\hline 25 & $\mathbf{F}$ & 0.3 & 0.5 & $0 \cdot 4(33)$ & $0 \cdot 4(-20)$ & 53 & $0.5(67)$ & $0 \cdot 65(30)$ & 37 \\
\hline 26 & $\mathbf{M}$ & 0.4 & 0.65 & $0 \cdot 65(63)$ & $0 \cdot 8(23)$ & 40 & $0 \cdot 8(100)$ & $0.65(0)$ & 100 \\
\hline 27 & $\mathbf{M}$ & $0 \cdot 6$ & $0 \cdot 7$ & $0 \cdot 7(16)$ & $0.9(28)$ & $(-12)$ & $0.9(50)$ & $1 \cdot 0(43)$ & 7 \\
\hline 28 & $\mathbf{M}$ & $0 \cdot 1$ & $0 \cdot 7$ & $0 \cdot 4(300)$ & $0 \cdot 7(0)$ & 300 & $0 \cdot 5(500)$ & $0 \cdot 7(0)$ & 500 \\
\hline 29 & $\mathbf{M}$ & $0 \cdot 4$ & $0 \cdot 8$ & $0.65(63)$ & $0 \cdot 7(-12)$ & 63 & $0 \cdot 7(75)$ & $0 \cdot 7(-12)$ & 75 \\
\hline 30 & $\mathbf{M}$ & $0 \cdot 2$ & 0.6 & $0.4(100)$ & $0 \cdot 6(0)$ & 100 & $0 \cdot 5(150)$ & $0 \cdot 6(0)$ & 150 \\
\hline 31 & $\mathbf{F}$ & $0 \cdot 1$ & $0 \cdot 7$ & $0 \cdot 2(100)$ & $0.7(0)$ & 100 & $0.5(400)$ & $0 \cdot 7(0)$ & 400 \\
\hline \multirow[t]{2}{*}{32} & $\mathbf{M}$ & $0 \cdot 3$ & $0 \cdot 7$ & $0.45(50)$ & $.0 \cdot 7(0)$ & 50 & 0.7 (133) & $0.7(0)$ & 133 \\
\hline & & $0 \cdot 30 \pm 0 \cdot 17$ & $0 \cdot 67 \pm 0.09$ & $0 \cdot 48 \pm 0 \cdot 17$ & $0 \cdot 69 \pm 0 \cdot 15$ & $89 \cdot 8 \pm 89 \cdot 9$ & $0 \cdot 64 \pm 0 \cdot 16$ & $0 \cdot 71 \pm 0 \cdot 12$ & $175 \cdot 3 \pm 177$ \\
\hline
\end{tabular}




\begin{tabular}{|c|c|c|c|c|c|c|c|c|c|}
\hline \multicolumn{3}{|c|}{ ollow-up 6 months } & \multicolumn{3}{|c|}{ Near VA, amblyopic } & \multicolumn{3}{|c|}{ Binocular functions } & \multirow[t]{2}{*}{ Remarks } \\
\hline 1mblyopic & Best & Effect $(\%)$ & Before & $\begin{array}{l}\text { End of } \\
\text { CAM }\end{array}$ & $\begin{array}{l}6 \\
\text { months }\end{array}$ & Before & $\begin{array}{l}\text { End of } \\
C A M\end{array}$ & $\begin{array}{l}6 \\
\text { months }\end{array}$ & \\
\hline $1.9(80)$ & $\begin{array}{l}1 \cdot 0(25) \\
* \\
*\end{array}$ & * & $\begin{array}{l}* \\
* \\
4\end{array}$ & $\begin{array}{l}1 \\
4 \\
3\end{array}$ & $\begin{array}{l}1 \\
* \\
*\end{array}$ & $\begin{array}{r}+ \\
60 \\
480\end{array}$ & $\begin{array}{r}+ \\
60 \\
240\end{array}$ & +60 & $\begin{array}{l}10 \text { CAM sessions. Micro ET. Stereo neg. } \\
\text { No treatment after CAM } \\
6 \text { CAM sessions. Intermit. XT. Occlusion after CAM } \\
\text { 10CAM sessions. Intermit. XT. Occlusion after CAM }\end{array}$ \\
\hline $\begin{array}{l}1.5(500) \\
1.5(150) \\
1.5(67) \\
1.7(600) \\
1.62+0.18\end{array}$ & $\begin{array}{l}0 \cdot 7(-12) \\
0 \cdot 5(0) \\
0 \cdot 8(0) \\
1 \cdot 0(0) \\
0 \cdot 80+0 \cdot 21\end{array}$ & $\begin{array}{l}500 \\
150 \\
67 \\
600 \\
274 \cdot 4+256 \cdot 7\end{array}$ & $\begin{array}{r}11 \\
11 \\
5 \\
12\end{array}$ & $\begin{array}{r}10 \\
6 \\
3 \\
10\end{array}$ & $\begin{array}{l}4 \\
2 \\
1 \\
2\end{array}$ & $\begin{array}{l}1000 \\
480 \\
- \\
-\end{array}$ & $\begin{array}{c}1000 \\
480 \\
(+)\end{array}$ & $\begin{array}{l}1000 \\
240 \\
(+) \\
+\end{array}$ & $\begin{array}{l}11 \text { CAM sessions. Micro ET. Occlusion after CAM } \\
6 \text { CAM sessions. Micro XT. Occlusion after CAM } \\
15 \text { CAM sessions. ET. Occlusion after CAM } \\
11 \text { CAM sessions. ET. Occlusion after CAM }\end{array}$ \\
\hline
\end{tabular}

Statistical analysis of the results obtained at followup in the subgroups of strabismic and anisometropic amblyopia, and in all groups of children, did not reveal any differences in visual acuity that depended on the mode of initial treatment, whether CAM or occlusion. It should be noted that visual acuity continued to improve during the follow-up period and that longer treatment periods were needed for maximal visual improvement in strabismic patients than in anisometropic patients (Fig. 2).

NEAR VISUAL ACUITY OF THE AMBLYOPIC EYE Visual acuity for near vision was not tested systematically. As a rule it increased during the initial treatment period with both CAM and occlusion. In most cases near visual acuity was found to be further improved at follow-up in the same way as the distance visual acuity (Tables $1-3$ ).

\section{BINOCULAR FUNCTIONS}

Children with anisometropia and central fixation usually had moderate or good stereoscopic vision, which was further increased by amblyopia treatment. The improvement in stereopsis generally parallelled the increase in visual acuity as seen in Table 1. Among children with strabismic amblyopia only those with exotropia showed any stereopsis (Table 2). As expected, very little improvement in binocularity was observed even after occlusion treatment, in spite of visual acuity improvements.

\section{EFFECTS OF TREATMENT ON FIXATION}

Eccentric fixation was observed in 6 children (Table $3)$. Of those treated with CAM, fixation improved in 2/3 during CAM, but not until occlusion was instituted in the third child of this group. With occlusion as the initial therapy fixation was centralised within 2-3 months in 2 children but remained eccentric in a third child.

\section{Discussion}

We have treated 4-year-old amblyopic children with grating stimulation (CAM treatment) or occlusion and found that the improvement in visual acuity was about the same with grating stimulation therapy lasting between 4 and 8 weeks as with 6 weeks of facial occlusion or occlusion with dimming (Einschleich) filters. This confirms the findings of Nyman et al. ${ }^{3}$

The 4-year-old, previously untreated amblyopic children were subdivided with respect to amblyopia types and fixation pattern, and each child was

\begin{tabular}{|c|c|c|c|c|c|c|c|c|c|}
\hline \multicolumn{3}{|c|}{ ᄃollow-up 6 months } & \multicolumn{3}{|c|}{ Near VA, amblyopic } & \multicolumn{3}{|c|}{ Binocular functions } & \multirow[t]{2}{*}{ Remarks } \\
\hline 4 mblyopic & Best & Effect $(\%)$ & Before & $\begin{array}{l}\text { After } \\
6 \text { weeks }\end{array}$ & $\begin{array}{l}6 \\
\text { months }\end{array}$ & Before & $\begin{array}{l}\text { After } \\
6 \text { weeks }\end{array}$ & $\begin{array}{l}6 \\
\text { months }\end{array}$ & \\
\hline$) \cdot 5(67)$ & $0 \cdot 65(30)$ & 37 & $*$ & * & $*$ & * & * & * & ET. Einschleich occlusion \\
\hline $1 \cdot 0(167)$ & $0 \cdot 8(23)$ & 144 & $*$ & 1 & $*$ & + & $*$ & + & ET. Einschleich occlusion \\
\hline $1 \cdot 0(67)$ & $1 \cdot 0(43)$ & 24 & 3 & 4 & 1 & - & - & - & ET. Occlusion \\
\hline$) \cdot 8(800)$ & $0.7(0)$ & 800 & 13 & 10 & 5 & - & + & + & ET. Occlusion \\
\hline$) \cdot 7(75)$ & $0 \cdot 7(-12)$ & 75 & 6 & 3 & * & 0 & $(+)$ & + & ET. Occlusion. Op at 3 months. Postop. only glasses \\
\hline$) \cdot 5(150)$ & $0.65(8)$ & 142 & 13 & 2 & 2 & $(+)$ & + & + & Micro ET. Occlusion \\
\hline$) \cdot 5(400)$ & $0.8(14)$ & 386 & 12 & 10 & * & $(+)$ & $(+)$ & + & Micro ET. Occlusion \\
\hline$) \cdot 9(200)$ & $0.9(28)$ & 172 & 7 & 5 & 1 & 480 & 480 & 240 & Micro ET. Occlusion \\
\hline$) \cdot 71 \pm 0 \cdot 21$ & $0 \cdot 78 \pm 0 \cdot 13$ & $222 \cdot 5 \pm 259 \cdot 4$ & & & & & & & \\
\hline
\end{tabular}


Table 3A Strabismus and anisometropia with eccentric fixation; CAM-treatment

\begin{tabular}{|c|c|c|c|c|c|c|c|c|c|}
\hline \multirow[t]{2}{*}{ Pat. } & \multirow[t]{2}{*}{$\operatorname{Sex}$} & \multicolumn{2}{|c|}{$\begin{array}{l}\text { Distance VA before } \\
\text { treatm. }\end{array}$} & \multicolumn{3}{|c|}{$\begin{array}{l}\text { Distance } V A \text { (change in \%) } \\
\text { End of } C A M\end{array}$} & \multicolumn{3}{|c|}{ Follow-up 3 months } \\
\hline & & Amblyopic & Best & Amblyopic & Best & Effect $(\%)$ & Amblyopic & Best & Effect $(\%)$ \\
\hline 33 & $\mathrm{~F}$ & $0 \cdot 1$ & $0 \cdot 6$ & $0 \cdot 4(300)$ & $0 \cdot 7(17)$ & 283 & $0 \cdot 3(200)$ & $0 \cdot 7(17)$ & 183 \\
\hline
\end{tabular}

Table 3B Strabismus with eccentric fixation; CAM-treatment

\begin{tabular}{|c|c|c|c|c|c|c|c|c|c|}
\hline \multirow[t]{2}{*}{ Pat. } & \multirow[t]{2}{*}{ Sex } & \multicolumn{2}{|c|}{$\begin{array}{l}\text { Distance VA before } \\
\text { treatm. }\end{array}$} & \multicolumn{3}{|c|}{$\begin{array}{l}\text { Distance VA (change in \%) } \\
\text { End of } C A M\end{array}$} & \multicolumn{3}{|c|}{ Follow-up 3 months } \\
\hline & & Amblyopic & Best & Amblyopic & Best & Effect $(\%)$ & Amblyopic & Best & Effect $(\%)$ \\
\hline 34 & $\mathbf{M}$ & $0 \cdot 1$ & $0 \cdot 45$ & $0 \cdot 1(0)$ & $0 \cdot 4(-11)$ & 0 & $0 \cdot 3(200)$ & $0 \cdot 4(-11)$ & 200 \\
\hline
\end{tabular}

Table 3C Anisometropia with eccentric fixation; CAM-treatment

\begin{tabular}{|c|c|c|c|c|c|c|c|c|c|}
\hline \multirow[t]{2}{*}{ Pat. } & \multirow[t]{2}{*}{ Sex } & \multicolumn{2}{|c|}{$\begin{array}{l}\text { Distance } V A \text { before } \\
\text { treatm. }\end{array}$} & \multicolumn{3}{|c|}{$\begin{array}{l}\text { Distance VA (change in \%) } \\
\text { End of } C A M\end{array}$} & \multicolumn{3}{|c|}{ Follow-up 3 months } \\
\hline & & Amblyopic & Best & Amblyopic & Best & Effect $(\%)$ & Amblyopic & Best & Effect $(\%)$ \\
\hline 35 & $\mathbf{M}$ & 0.04 & $0 \cdot 8$ & $0 \cdot 3(600)$ & $0.8(0)$ & 600 & $0 \cdot 3(600)$ & $0 \cdot 8(0)$ & 600 \\
\hline
\end{tabular}

For explanation see Table $1 \mathrm{~A}$.

allocated to the CAM or the occlusion group in a randomised fashion. In this way we obtained comparable groups of children with regard also to initial visual acuity level and binocular functions. In all previous studies, reviewed by Mehdorn et al.,7 Schor et al., ${ }^{2}$ Crandall et al. ${ }^{8}$ and Nyman et al.,${ }^{3}$ the comparison of treatment effects has been done on much more heterogeneous groups of amblyopic children, and this might have affected the results. We noted a slightly better effect from CAM than from occlusion therapy in anisometropic amblyopia. Measured as a percentage, the increase in visual acuity ranged between 50 and $90 \%$ for the different groups with central fixation, which is somewhat higher than for older children treated with CAM. ${ }^{6}$

Conventional amblyopia therapy with occlusion or penalisation was used after the initial period in the majority of the children. CAM treatment was maintained until no further improvement in visual acuity was seen, according to the recommendations of Watson et al. ${ }^{5}$ Examinations at 3 and 6 months after initiating treatment revealed further improvement in visual acuity, particularly in strabismic amblyopia. The increase in visual acuity was the same irrespective of whether the children had been treated with CAM or with occlusion during the initial period. We noted that full visual recovery was obtained faster in anisometropic than in strabismic amblyopia. The initial acuity level was also lower in strabismic than in anisometropic children. This is probably due to a deleterious effect of abnormal binocular interaction in the strabismus cases. ${ }^{9}$ In the anisometropic group the main amblyogenic factor might have been a blurred image in the amblyopic eye, since binocular functions were well maintained in spite of amblyopia.

It now seems well established that the grating pattern in itself does not contribute to the effect of CAM treatment. Instead it is probably the short 


\begin{tabular}{|c|c|c|c|c|c|c|c|c|c|}
\hline \multicolumn{3}{|c|}{ ollow-up 6 months } & \multicolumn{3}{|c|}{ Near $V A$, amblyopic } & \multicolumn{3}{|c|}{ Binocular functions } & \multirow[t]{2}{*}{ Remarks } \\
\hline mblyopic & Best & Effect $(\%)$ & Before & $\begin{array}{l}\text { End of } \\
\text { CAM }\end{array}$ & $\begin{array}{l}6 \\
\text { months }\end{array}$ & Before & $\begin{array}{l}\text { End of } \\
C A M\end{array}$ & $\begin{array}{l}6 \\
\text { months }\end{array}$ & \\
\hline$\cdot 3(200)$ & $0 \cdot 8(33)$ & 167 & 10 & 3 & 10 & - & - & - & $\begin{array}{l}16 \text { CAM sessions. ET. Occlusion after CAM. } \\
\text { Fixation improved from nasal to central during CAM }\end{array}$ \\
\hline
\end{tabular}

\begin{tabular}{|c|c|c|c|c|c|c|c|c|c|}
\hline \multicolumn{3}{|c|}{ ollow-up 6 months } & \multicolumn{3}{|c|}{ Near VA, amblyopic } & \multicolumn{3}{|c|}{ Binocular functions } & \multirow[t]{2}{*}{ Remarks } \\
\hline Imblyopic & Best & Effect $(\%)$ & Before & $\begin{array}{l}\text { End of } \\
C A M\end{array}$ & $\begin{array}{l}6 \\
\text { months }\end{array}$ & Before & $\begin{array}{l}\text { End of } \\
C A M\end{array}$ & $\begin{array}{l}6 \\
\text { months }\end{array}$ & \\
\hline $1 \cdot 3(200)$ & $0 \cdot 5(11)$ & 189 & 13 & 13 & 8 & + & + & + & $\begin{array}{l}10 \text { CAM sessions. ET. Occlusion after CAM. } \\
\text { Fixation unchanged during CAM but improved from } \\
\text { nasal to central during occlusion }\end{array}$ \\
\hline
\end{tabular}

\begin{tabular}{|c|c|c|c|c|c|c|c|c|c|}
\hline \multicolumn{3}{|c|}{ 'ollow-up 6 months } & \multicolumn{3}{|c|}{ Near VA, amblyopic } & \multicolumn{3}{|c|}{ Binocular functions } & \multirow{2}{*}{ Remarks } \\
\hline Imblyopic & Best & Effect (\%) & Before & $\begin{array}{l}\text { End of } \\
C A M\end{array}$ & $\begin{array}{l}6 \\
\text { months }\end{array}$ & Before & $\begin{array}{l}\text { End of } \\
C A M\end{array}$ & $\begin{array}{l}6 \\
\text { months }\end{array}$ & \\
\hline $1 \cdot 3(600)$ & $0 \cdot 8(0)$ & 600 & 12 & 7 & 7 & 240 & 240 & 120 & $\begin{array}{l}7 \text { CAM sessions. Occlusion after CAM. } \\
\text { Fixation improved from paracentral superior to } \\
\text { central during CAM }\end{array}$ \\
\hline
\end{tabular}

periods of occlusion in combination with demanding visual tasks that is important. ${ }^{27810}$ Animal experiments have shown that the response specificity of visual cortex neurons can be markedly sharpened during the alerting reaction. ${ }^{\text {" }}$ Possibly similar mechanisms are involved in the CAM type of amblyopia treatment, as well as in other regimens of 'minimal occlusion' with concentrated visual activity of the amblyopic eye during the occlusion period. It has been reported that visual improvement from 'minimal occlusion' is almost as good as from fulltime occlusion, ${ }^{5}$ and our results confirm these observations.

In conclusion, this study on 4-year-old amblyopic children has shown that CAM treatment, or rather 'minimal occlusion' combined with exercises of concentrated visuomotor activity, seemed as effective in improving visual acuity as full-time occlusion, during the initial amblyopia treatment period. In anisometropia with central fixation a rather short treatment period is usually sufficient, and in this type of amblyopia CAM can be of value. However, strabismic amblyopia treatment has to be continued longer in order to maintain the visual acuity and to improve it further, and the maximal treatment effect cannot be reached with CAM stimulation alone. The same holds for amblyopia with eccentric fixation. Conventional therapy in some form has to be continued. Therefore 'minimal occlusion', i.e., in the form of CAM therapy, can be a valuable adjunct in the treatment of anisometropic amblyopia, but it cannot be regarded as the main form of treatment for amblyopia. In our opinion this should still be full-time occlusion.

This study was supported by grants from the Research Committee of Ostergötlands läns landsting and the Swedish Medical Research Council (no. 4751). We thank the orthoptists in our departments for valuable assistance during the course of this study. 
Table 3D Strabismus and anisometropia with eccentric fixation; occlusion treament

\begin{tabular}{|c|c|c|c|c|c|c|c|c|c|}
\hline \multirow[t]{2}{*}{ Pat. } & \multirow[t]{2}{*}{ Sex } & \multicolumn{2}{|c|}{$\begin{array}{l}\text { Distance } V A \text { before } \\
\text { treatm. }\end{array}$} & \multicolumn{3}{|c|}{$\begin{array}{l}\text { Distance VA (change in \%) } \\
\text { After } 6 \text { weeks }\end{array}$} & \multicolumn{3}{|c|}{ Follow-up 3 months } \\
\hline & & Amblyopic & Best & Amblyopic & Best & Effect $(\%)$ & Amblyopic & Best & Effect (\%) \\
\hline 36 & $\mathbf{M}$ & $0 \cdot 06$ & $0 \cdot 7$ & $0 \cdot 3(400)$ & $0 \cdot 8(14)$ & 386 & $0 \cdot 6(900)$ & $0 \cdot 8(14)$ & 886 \\
\hline 37 & $\mathbf{F}$ & $0 \cdot 04$ & $0 \cdot 8$ & $0 \cdot 1(150)$ & $0 \cdot 9(12)$ & 138 & $0 \cdot 08(100)$ & $0 \cdot 9(12)$ & 88 \\
\hline
\end{tabular}

Table 3E Strabismus with eccentric fixation; occlusion treatment

\begin{tabular}{|c|c|c|c|c|c|c|c|c|c|}
\hline \multirow[t]{2}{*}{ Pat. } & \multirow[t]{2}{*}{ Sex } & \multicolumn{2}{|c|}{$\begin{array}{l}\text { Distance } V A \text { before } \\
\text { treatm. }\end{array}$} & \multicolumn{3}{|c|}{$\begin{array}{l}\text { Distance VA } \\
\text { After } 6 \text { weeks }\end{array}$} & \multicolumn{3}{|c|}{ Follow-up 3 months } \\
\hline & & Amblyopic & Best & Amblyopic & Best & Effect (\%) & Amblyopic & Best & Effect $(\%)$ \\
\hline 38 & $\mathbf{M}$ & $0 \cdot 08$ & $0 \cdot 6$ & $0 \cdot 1(25)$ & $0 \cdot 6(10)$ & 15 & $0.4(400)$ & $0 \cdot 7(17)$ & 383 \\
\hline
\end{tabular}

For explanation see Table 1A.

Fig. 1 Effects of amblyopia treatment on distance visual acuity. Changes after CAM treatment or after the initial period of occlusion treatment are represented. Visual acuity in Snellen decimal notation before treatment on the abscissa and after treatment on the ordinate. Each point represents the acuities of the amblyopic eye of one patient (or in a few cases 2 patients as marked). The diagonal in the diagrams is the non-improvement line.

A: The group of children with anisometropia and central fixation, also represented in Table 1. Open symbols indicate CAM treatment, filled symbols occlusion.

B: Children with strabismic amblyopia and central fixation, also presented in Table 2. Open symbols-CAM, filled symbols-occlusion.

C: Children with eccentric

fixation. Circles represent anisometropia, triangles strabismus, and squares anisometropia plus strabismus Open symbols-CAM, filled symbols-occlusion. The results from these children are also shown in Table 3.
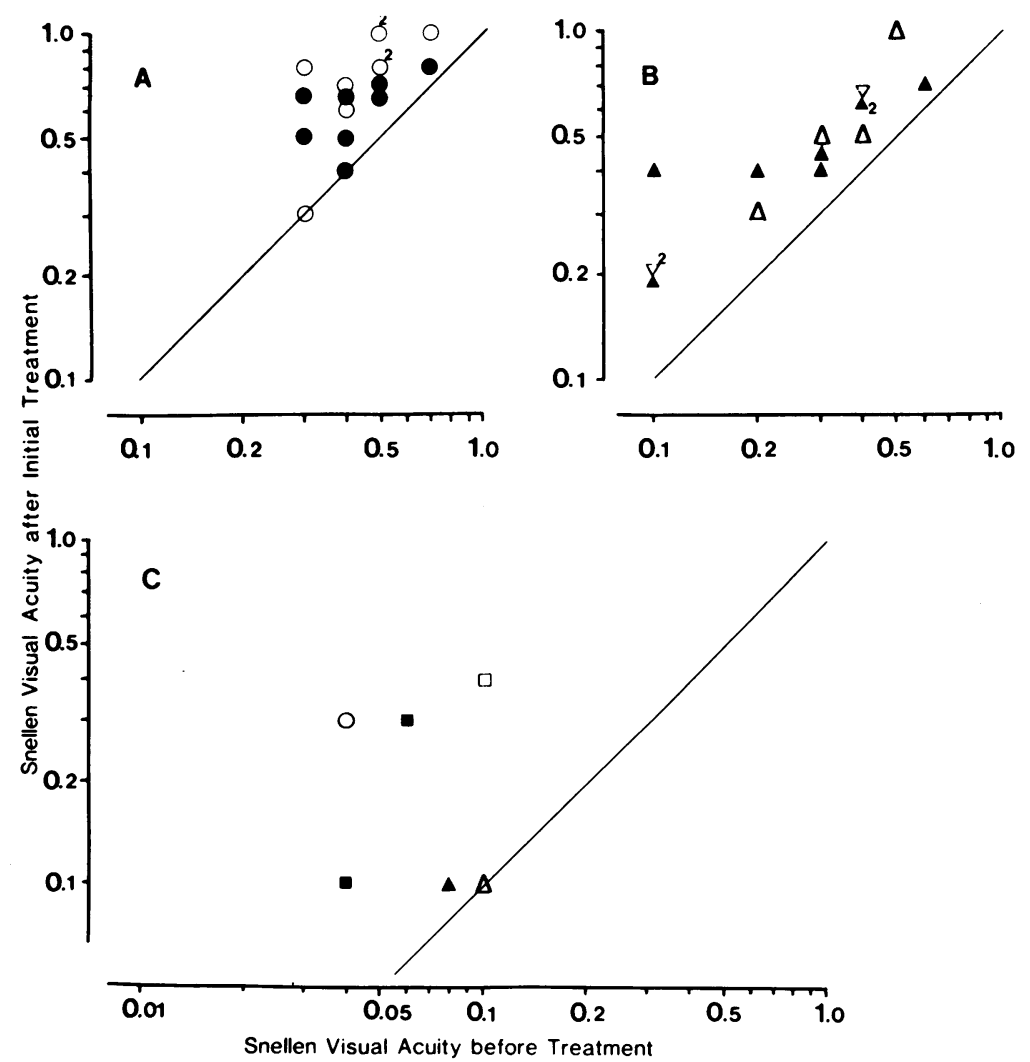


\begin{tabular}{|c|c|c|c|c|c|c|c|c|c|}
\hline \multicolumn{3}{|c|}{ ollow-up 6 months } & \multicolumn{3}{|c|}{ Near VA, amblyopic } & \multicolumn{3}{|c|}{ Binocular functions } & \multirow[t]{2}{*}{ Remarks } \\
\hline Imblyopic & Best & Effect $(\%)$ & Before & $\begin{array}{l}\text { After } \\
6 \text { weeks }\end{array}$ & $\begin{array}{l}6 \\
\text { months }\end{array}$ & Before & $\begin{array}{l}\text { After } \\
6 \text { weeks }\end{array}$ & $\begin{array}{l}6 \\
\text { months }\end{array}$ & \\
\hline $6(900)$ & $0 \cdot 8(14)$ & 896 & * & 7 & * & $\begin{array}{l}- \\
+\end{array}$ & $\begin{array}{l}(+) \\
+\end{array}$ & $\begin{array}{l}(+) \\
+\end{array}$ & $\begin{array}{l}\text { ET. Occlusion. Fixation improved from temporal to } \\
\text { central within } 2 \text { months. } \\
\text { Micro ET. Occlusion successful during initial period } \\
\text { but not later. Fixation unchanged. }\end{array}$ \\
\hline
\end{tabular}

\begin{tabular}{|c|c|c|c|c|c|c|}
\hline ollow-up 6 months & & Near VA & 4. amblyopic & Binocul & ar functions & Remarks \\
\hline mblyopic Best & Effect $(\%)$ & Before & $\begin{array}{ll}\text { After } & 6 \\
6 \text { weeks } & \text { months }\end{array}$ & Before & $\begin{array}{ll}\text { After } & 6 \\
6 \text { weeks } & \text { months }\end{array}$ & \\
\hline
\end{tabular}

\begin{tabular}{|c|c|c|c|c|c|c|c|c|c|}
\hline$-4(4(x))$ & $0 \cdot 8(33)$ & 367 & 13 & 13 & 2 & * & $*$ & $*$ & $\begin{array}{l}\text { ET. Occlusion for } 3 \text { months; later penalisation. } \\
\text { Fixation improved from nasal to central after } 3 \text { months }\end{array}$ \\
\hline
\end{tabular}

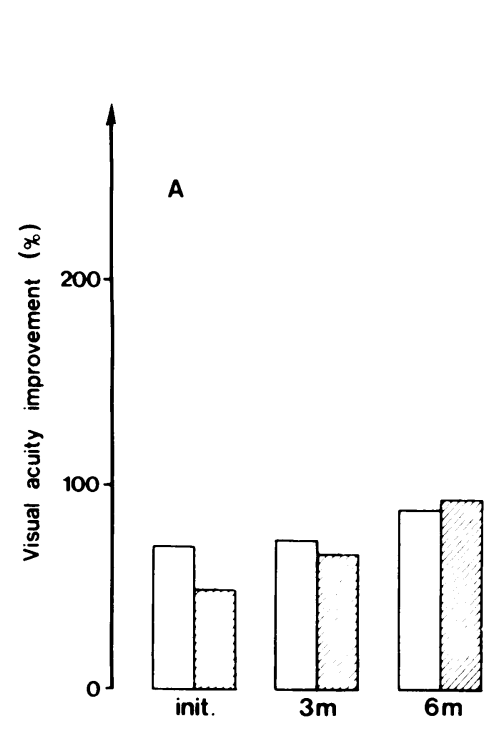

Fig. 2 The effect of amblyopia treatment during follow-up, expressed as the change in distance visual acuity as a percentage of the initial value. This is a graphic representation of the results also presented in Tables 1 and 2.

Unfilled bars mark the mean values in the CAM treatment groups and hatched bars mean values of the full-time occlusion groups. 'Init.' indicates the initial treatment period, i.e., 4-8 weeks for CAM and 6 weeks for occlusion.

A: Children with anisometropic' amblyopia and central fixation (see also Table 1). Effect of CAM significantly better than effect of occlusion during initial period $(p=0.05)$. At 3 and 6 months no difference between groups.

B: Children with strabismic amblyopia and central fixation (see also Table 2). No difference between treatment groups at any of the examinations. 


\section{References}

1 Campbell FW, Hess RF, Watson PG, Banks R. Preliminary results of a physiologically based treatment of amblyopia. $\mathrm{Br} J$ Ophthalmol 1978; 62: 748-55.

2 Schor C, Gibson J, Hsu M, Mah M. The use of rotating gratings for the treatment of amblyopia: a clinical trial. Am J Optom Physiol Opt 1981; 58: 930-8.

3 Nyman KG, Sing NG, Rydberg A, Fornander M. A controlled study comparing CAM treatment to occlusion therapy. In: Reinecke R, ed., Trans IV Intern Congr Strabismus in press.

4 Hedin A, Nyman KG, Derouet B. A modified letter matching chart for testing young children's visual acuity. J Pediatr Ophthalmol 1980; 17: 114-8.

5 Watson PG, Banks RV, Campbell FW, Hess RF. Clinical assessment of a new treatment for amblyopia. Trans Ophthalmol Soc UK 1978; 98: 201-8.
6 Lennerstrand G, Kvarnström G, Lundh BL, Wranne K. Effects of grating stimulation on visual acuity in amblyopia. Acta Ophthalmol (Kbh) 1981; 59: 179-88.

7 Mehdorn E, Mattheus S, Schuppe A, Klein U, Kommerell G. Treatment for amblyopia with rotating gratings and subsequent occlusion: a controlled study. Int Ophthalmol 1981; 3: 161-6.

8 Crandall MA, Cibis GW, Ellerhorst B. CAM (stripe) therapy for amblyopia. Perspect Ophthalmol 1981; 5: 51-5.

9 von Noorden GK. Amblyopia: basic concepts and current treatment. In: Symposium on strabismus (Trans New Orlean Acad Ophthalmol. St Louis: Mosby, 1978: 1-14.

10 Keith CG, Howell ER, Mitchell DE, Smith S. Clinical trial of the use of rotating grating patterns in the treatment of amblyopia. $\mathrm{Br}$ J Ophthalmol 1980; 64: 597-606.

11 Livingstone MS, Hubel DH. Effects of sleep and arousal on the processing of visual information in the cat. Nature 1981; 291: $554-61$ 